\title{
ANALYTICAL MODEL FOR THE PERFORMANCE ESTIMATION OF PRE- COOLED PULSE DETONATION TURBOFAN ENGINES
}

\author{
Carlos Xisto, Fakhre Ali, Olivier Petit and \\ Tomas Grönstedt \\ Department of Mechanics and Maritime Sciences \\ Chalmers University of Technology \\ Gothenburg, Sweden
}

\author{
Anders Lundbladh \\ GKN Aerospace \\ Trollhättan, Sweden
}

\author{
Andrew Rolt \\ Cranfield University \\ Bedfordshire, UK
}

\section{ABSTRACT}

This paper proposes a pulse detonation combustion (PDC) model integrated within Chalmers University's gas turbine simulation tool GESTPAN (GEneral Stationary and Transient Propulsion ANalsysis). The model will support the development of novel aircraft engine architectures exploiting the synergies between intercooling, aftercooling and PDC. The proposed engine architectures are based on a reference high bypass ratio geared-turbofan engine model with performance levels estimated to be available by year 2050. Parametric studies have been carried out for each proposed advanced architecture, providing engine cycle mid-cruise design point parameters. Design sensitivity studies related to intercooling technology in combination with a PDC are further explored for a number of heat-exchanger design effectiveness values and associated pressure loss levels. The acquired results suggest that the incorporation of PDC technology within a conventional core has the potential to significantly improve engine thermal efficiency. Incorporating intercooling improves the cycle performance for any pre-combustion $O P R$ above 10 and contributes to an increase in specific power over the entire range of OPR. Finally, the results demonstrate that aftercooling the high pressure compressor delivery air further improves core specific power, but cancels out any SFC and thermal efficiency benefits arising from pulse detonation.

\section{NOMENCLATURE}

$c_{b} \quad$ Speed of sound of products, $\mathrm{m} / \mathrm{s}$.

$c_{f} \quad$ Speed of sound for fuel-air mixture, $\mathrm{m} / \mathrm{s}$.

$c_{g} \quad$ Speed of sound for purge air, $\mathrm{m} / \mathrm{s}$.

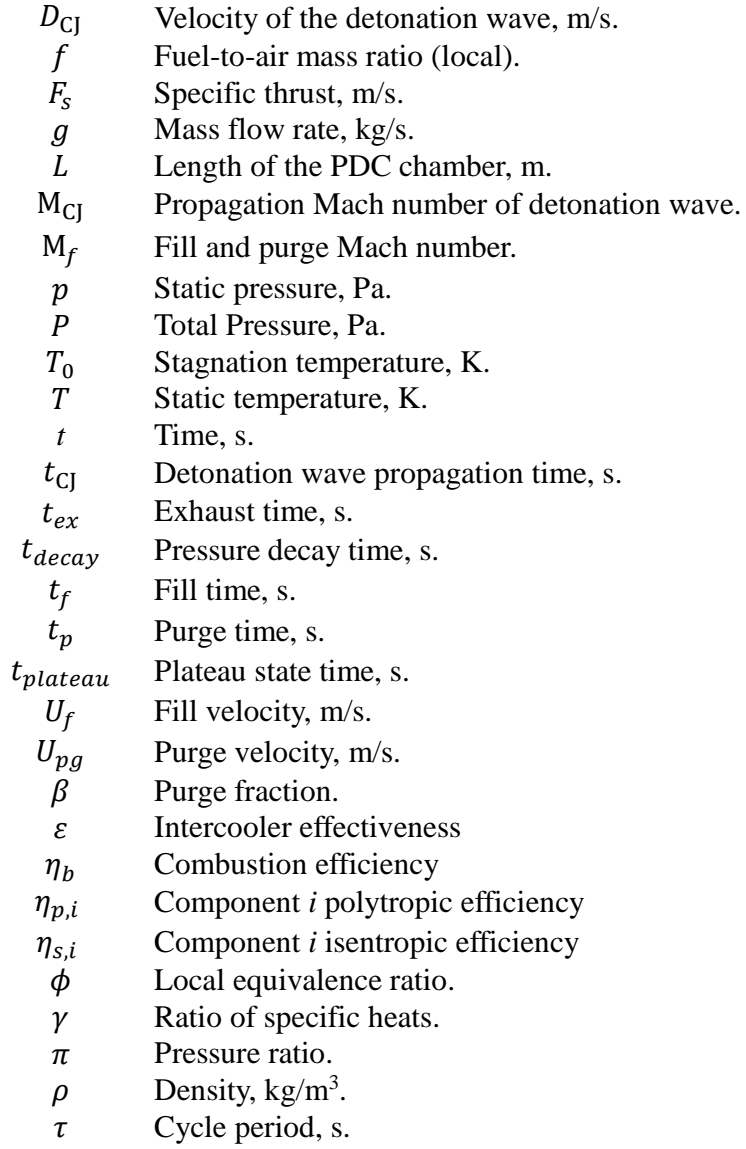




\section{Acronyms}

$\begin{array}{ll}\text { AC } & \text { Aftercooler } \\ \text { BPR } & \text { Bypass ratio } \\ \text { CEA } & \text { Chemical Equilibrium with Applications } \\ \text { FPR } & \text { Fan Pressure Ratio } \\ \text { HPC } & \text { High Pressure Compressor } \\ \text { IPC } & \text { Intermediate Pressure Compressor } \\ \text { IC } & \text { Intercooler } \\ \text { LHV } & \text { Lower Heating Value } \\ \text { OPR } & \text { Overall Pressure Ratio (compression) } \\ \text { PDC } & \text { Pulse Detonation Combustor } \\ \text { SFC } & \text { Specific Fuel Consumption, } \mathrm{mg} /(\mathrm{N} \cdot \mathrm{s}) \\ \text { TET } & \text { Turbine Entry Temperature, } \mathrm{K}\end{array}$

\author{
Subscripts \\ 1-138 Station designation shown in Fig. 5 \\ $4 \quad$ PDC Cycle averaged properties \\ $b \quad$ Plateau state \\ $s \quad$ Scavenge state \\ CJ Chapman-Jouguet state \\ in Initial condition (prior to detonation)
}

\section{INTRODUCTION}

In Europe the H2020 ULTIMATE (Ultra Low emission Technology Innovations for Mid-century Aircraft Turbine Engines) project [1] is exploring synergistic combinations of radical technologies to target reductions in all three major loss sources in a state-of-the-art 2015 aero-engine [2]: $i$ ) combustor irreversibility; ii) core exhaust heat rejection; and iii) excess of kinetic energy in the propulsive jets.

To address loss source iii), high bypass ratio geared turbofans are being investigated [3] as well as counter-rotating open rotors [4]. With regards to loss source ii), introducing cooling within the compression system has been a widely adopted approach to enable higher overall pressure ratios (OPRs) for a given turbine entry temperature (TET) [5, 6]. This can be seen as an indirect means of targeting the loss from core exhaust heat rejection, since higher turbine expansion ratios lead to reduced core exhaust temperatures. Intercooling in gas turbine aero-engines has been the subject of extensive research in several EU research projects with recent results revealing that improvements in fuel burn efficiency of the order of $3-5 \%$ are achievable [5, 7].

In terms of addressing loss source $i$ ), the entropy generation of a conventional combustor can be reduced by adding a topping cycle [8] or a pressure-rise combustion system such as a pulse detonation combustor (PDC) [9], see Fig. 1. A PDC is an unsteady combustion device that burns fuel through the propagation of axial intermittent detonation waves. The unsteady cyclic operation comprises several phases. An illustrative example of a typical PDC cycle is shown in Fig. 2:

a) Filling, the valve opens and the tube is filled with a uniform mixture of fuel-air at a given local equivalence ratio.

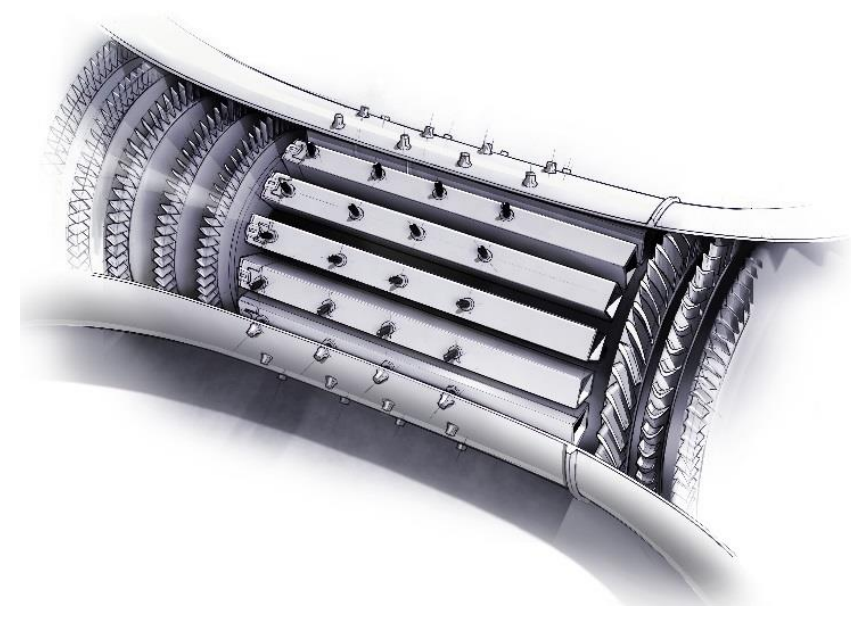
FIGURE 1 - ILLUSTARTION OF A PULSE DETONATION
CORE (CHALMERS UNIVERISTY).

b-c) Detonation and propagation, the valve closes and a detonation wave is initiated near the closed end of the tube. The wave will then travel towards the open end of the tube;

d-e) Blowdown, a rarefaction wave propagates towards the closed end of the tube, starting the exhaust process, until the initial (purge) pressure is reached. During blowdown the valve is still closed;

f) Purging, the valve is opened and HPC air is used to completely or partially purge the tube of the hot products of detonation.

To be able to operate in such conditions, a basic PDC typically comprises a set of straight channels of constant cross-section area arranged in a can-annular configuration around the engine core annulus, as illustrated in Fig. 1. Each channel includes a valve that controls the intake of working gas during purge and fill. A plenum/buffer volume (not visible in Fig. 1) is located between the high pressure compressor (HPC) and PDC. This volume serves to damp the pressure fluctuations arising from the unsteady operation of the detonation cycle, and it could also accommodate an aftercooler before combustion.

A fundamental thermodynamic analysis revealed that a PDC core has the theoretical potential to improve the thermal efficiency of a gas turbine cycle by 10 to $15 \%$ [9]. However the unsteady nature of a pulse detonation cycle results in strong variations in mass flow, thermodynamic quantities and rotor inlet angles [10], and it can even lead to periods of reversed flow [11]. This unsteady behavior poses numerous technical challenges when designing an effective combustor-turbine system and also when developing an effective system level model capable of modelling the behavior of a PDC under different operating conditions. 


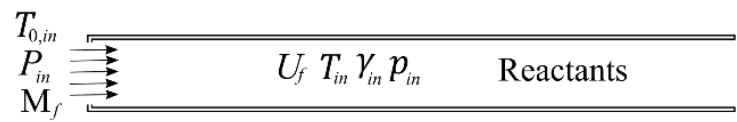

a)

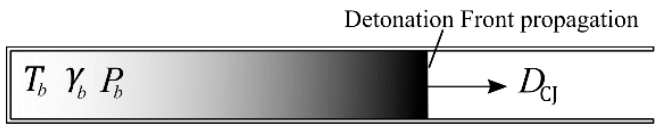

c)

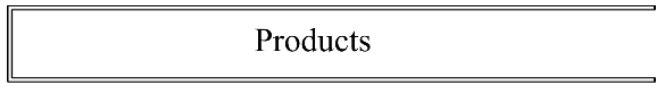

e)

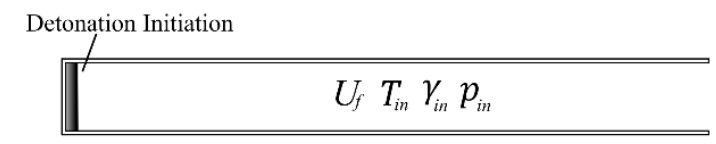

b)

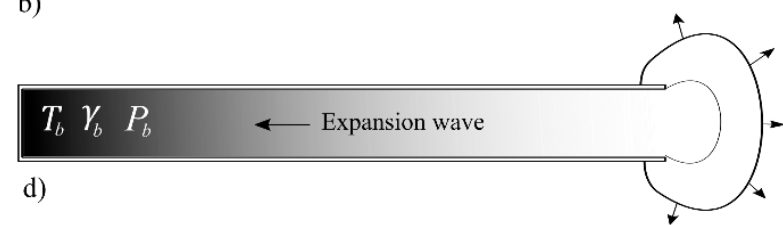

Purge Starts

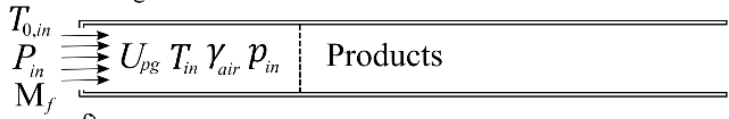

\section{FIGURE 2 - DIFFERENT PROCESSES OCCURRING IN THE PDC. A) FILLING ENDS; B-E) DETONATION PROPAGATION AND BLOWDOWN; F) PURGE STARTS}

Several models were developed to analyze the performance of pulse detonation engines. These included analytical formulations, which are based on time and mass averaged thermodynamic properties over a PDC cycle $[12,13]$, or derived using classical thermodynamic steady state analysis with features of pulse detonation flow incorporated $[9,14]$. Another class of models [15] utilized time-accurate CFD analysis including combustion reactions to generate performance maps that could easily be integrated into an engine performance tool [16]. These approaches were extensively validated for different operating conditions and shown to offer an efficient and robust way of predicting the performance of pulse detonation based engines.

Pulse detonation combustion offers a natural synergy with intercooling and aftercooling of the compression system. In constant volume combustion, reducing the combustor inlet temperature improves the volumetric efficiency of the system [17], allowing for more air-fuel to be combusted per engine cycle. Moreover, precooling the flow results in higher combustion pressure ratios [18], reduces the risk of predetonation and reduces the cooling requirements of the detonation core. These synergies indicate the possibility of a promising engine design targeting significant improvements in overall aero-engine performance levels. In the paper it is proposed, for the first time, to explore such synergies and to evaluate their impact in the performance levels of a long-range ultra-high bypass ratio turbofan.

\section{Scope of present work}

A recent exergy analysis [2] revealed that PDC together with intercooling and recuperation has the potential to reduce the engine losses and improve SFC by $18 \%$ relative to a conventional turbofan engine. From the preliminary design point of view, it is of great interest to further extend the assessment of the PDC technology and explore its performance characteristics within an integrated engine performance environment.
The work presented in this study proposes an integrated aero-engine performance evaluation model, developed for the conceptual design assessment of novel intercooled and aftercooled pulse detonation turbofan engines. The implemented environment is constructed by integrating an analytically derived PDC model within Chalmers University's in-house aero-engine performance simulation tool called GESTPAN (GEneral Stationary and Transient Propulsion ANalsysis) [19]. The mathematical formulation of the developed PDC model is based on the work of Endo et al. [13] and Wintenberger and Shepherd [12]. The model caters for the chemical equilibrium relations and gas dynamic theory to predict the PDC behavior in all phases of the pulse detonation cycle, and provides evaluation of the associated key parameters (i.e. pressure rise, outlet temperature, fuel mass flow and purge fraction). In previous studies the proposed methodology has been successfully applied to estimate the performance of single-tube air-breathing pulse detonation engines $[12,13]$ and to perform an exergy analysis on a stationary gas turbine architecture powered by a pulse detonation combustor [20]. In this study, the application of the methodology is further extended to analyze turbofan aeroengines incorporating a pulse detonation core. Additional validation of the model is carried out utilizing data acquired through in-house CFD simulations, and using published data for pulse detonation cores [21].

The overall approach is implemented for the conceptual design assessment of three advanced high bypass ratio turbofans engine architectures incorporating: A non-precooled pulse detonation combustor core (PDC); Intercooling and a pulse detonation core (IC-PDC); Intercooling and aftercooling with a pulse detonation core (IC-AC-PDC). A high bypass ratio geared turbofan incorporating a conventional combustion chamber has been employed as a reference year 2050 powerplant, and is estimated to represent the technology level for entry-into-service at year 2050. The technological assumptions incorporated for the performance estimation of the reference engine are represented 
through moderate improvements in TET, OPR and component efficiencies, supported by related public domain literature and a general consensus from ULTIMATE consortium industrial partners. The developed reference cycle provides a comparison case for the advanced cycles and a baseline model where the radical technologies (i.e. intercooling, aftercooling and PDC) can be integrated.

A number of parametric studies have been carried out for each proposed architecture, at mission mid-cruise conditions, in terms of engine design cycle and output parameters (i.e. OPR, BPR, combustion pressure ratio, purge fraction, SFC, thermal efficiency). Furthermore, design sensitivity studies related to intercooling technology in combination with PDC are further explored for a number of heat-exchanger design effectiveness values and associated pressure loss levels.

\section{PULSE DETONATION COMBUSTOR MODEL}

The different phases of a PDC can be represented by a timeseries of total pressure and mass-flow, as illustrated in Fig. 3. The present model computes the PDC cycle time-averaged mass weighted total pressure, together with mass-averaged temperature. Therefore, information concerning the thermodynamic properties during all phases of the PDC cycle is required. To support the development of the model the following assumptions are incorporated:

- The flow variations are considered to be significant only in the axial direction;

- The average mass storage over a cycle is zero;

- The valve opens and closes instantaneously, a simplified model for the valve loss is used;

- The fuel-air mixture and purge air are injected at subsonic speeds;

- The fuel is assumed to be homogeneously mixed with air, during the fill phase;

- Heat transfer and viscous effects are neglected;

- All processes, apart from the detonation wave are treated as isentropic;

- A self-sustained detonation is initiated near the closed end of the tubes.

The onset of detonation is affected by the initial properties of the flow, size of the detonation duct/tube and initiation energy. An approximate limiting value for the tube diameter is given by a direct relation with the detonation cell size. Previous work showed that the minimum diameter for reaching detonation, in stoichiometric hydrocarbon-air mixtures at 1 bar and $298 \mathrm{~K}$, is of the order of 50 to $100 \mathrm{~mm}$ [22]. If Deflagration to Detonation Transition (DDT) is considered for detonation initiation, then the tube length is a limiting factor. However the present model assumes the existence of a direct initiation mechanism, which enables the creation of a self-sustained detonation wave at the valve plane. This can be the subject of some controversy since direct initiation may require the deposition of prohibitive amounts of energy (it can be on the order of $200 \mathrm{~kJ}$ for butaneair [22]), making it unreasonable for practical applications.

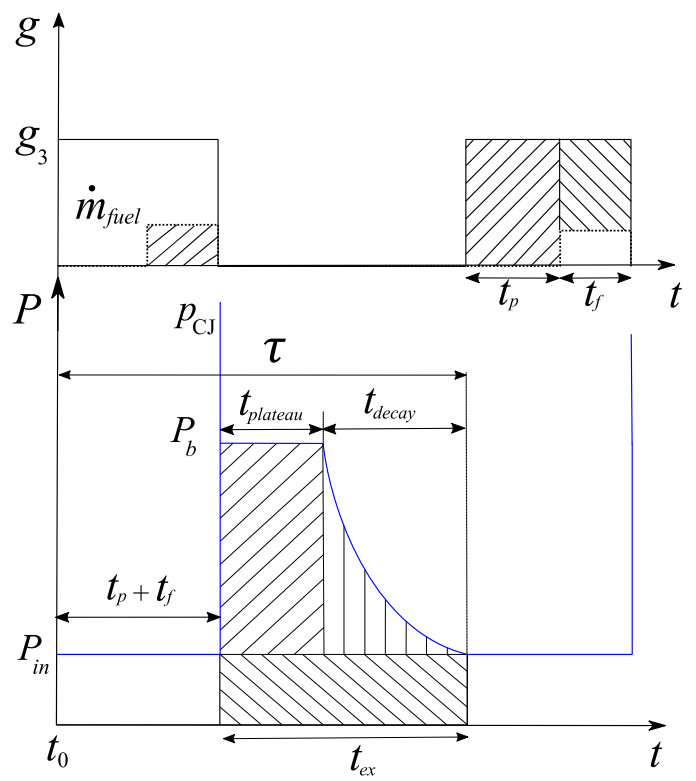

FIGURE 3 - PRESSURE AND MASS FLOW HISTORY AT THE VALVE PLANE.

Another solution is to use a small amount of energy to start deflagration and use a longer tube to allow transition to detonation. However, the DDT length can also be prohibitively high, and may require the implementation of DDT enabling obstacles, which then results in additional pressure losses. Some studies suggest that the pressure increase in the PDC is not itself limited by the DDT length due to the occurrence of a retonation wave that compresses the already burnt gases [23]. Still the necessary length of the tube to achieve DDT increases the combustor size, and the time required to achieve detonation limits the cycle frequency.

\section{Detonation properties}

An accurate prediction of detonation properties is essential to derive the flow behavior during all the phases of a PDC cycle. The behavior of these properties, with initial conditions (prior to detonation), are detailed in [18, 22] and are herein summarized: i) The peak values of pressure ratio, detonation velocity and detonation temperature are, for homogeneous hydrocarbon-air gaseous mixtures, achieved for over-stoichiometric mixtures. $\mathrm{ii}$ ) A decrease in initial temperature significantly increases the detonation pressure ratio. iii) Conversely, increasing the initial temperature results in small increments in detonation temperature and slightly decreases the detonation velocity. iv) The detonation velocity and detonation temperature slightly increase with the initial pressure. $v$ ) The detonation pressure ratio is almost independent of the initial pressure.

In the present implementation, the detonation properties are obtained with NASA's CEA (Chemical Equilibrium with Applications) code [24]. The inputs for CEA are static pressure, 


$$
p_{\text {in }}=\frac{P_{\text {in }}}{\left(1+0.5\left(\gamma_{\text {in }}-1\right) \mathrm{M}_{f}^{2}\right)^{\frac{\gamma_{\text {in }}}{\gamma_{\text {in }}-1}}}
$$

static temperature,

$$
T_{i n}=\frac{T_{0, i n}}{1+0.5\left(\gamma_{i n}-1\right) \mathrm{M}_{f}^{2}}
$$

and local equivalence ratio, $\phi$. In Eqns. (1-2) $P_{\text {in }}$ and $T_{0, \text { in }}$ are stagnation properties obtained at the HPC (or aftercooler) outlet, $\gamma_{\text {in }}$ is the ratio of specific heats for the fuel-air mixture and $\mathrm{M}_{f}$ is the fill and purge Mach number. Additional inputs are fuel (JetA) and oxidant (air) types. The outputs of CEA are the detonation Mach number, $\mathrm{M}_{\mathrm{CJ}}$, the detonation wave velocity, $\mathrm{D}_{\mathrm{CJ}}$, the ratio of specific heats for the combustion gases, $\gamma_{b}$, and the fuel-to-air ratio, $f$.

\section{Properties at the plateau state}

During detonation the flow is accelerated locally by the passing of the detonation wave. At the valve plane the flow is at rest, thus the gas is decelerated from the Chapman-Jouguet $(\mathrm{CJ})$ state until the plateau pressure, $P_{b}$, is reached. Such deceleration can be described by a Taylor expansion wave, which means that the state of the gas in the boundary of the deceleration wave can be described by a mathematical expression,

$$
P_{b}=\delta_{A 1} p_{\text {in }} \quad c_{b}=\frac{D_{\mathrm{CJ}}}{\delta_{A 2}}
$$

where

$$
\delta_{A 1}=\frac{\gamma_{i n} \mathrm{M}_{\mathrm{CJ}}^{2}+\gamma_{b}}{2 \gamma_{b}}\left(\frac{\gamma_{i n} \mathrm{M}_{\mathrm{CJ}}^{2}+\gamma_{b}}{\gamma_{i n} \mathrm{M}_{\mathrm{CJ}}^{2}+1} \cdot \frac{\gamma_{b}+1}{2 \gamma_{b}}\right)^{\frac{\left(\gamma_{b}+1\right)}{\left(\gamma_{b}-1\right)}}
$$

and,

$$
\delta_{A 2}=2 \frac{\gamma_{i n} \mathrm{M}_{\mathrm{CJ}}^{2}}{\gamma_{i n} \mathrm{M}_{\mathrm{CJ}}^{2}+\gamma_{b}}
$$

In the above formulation the two-gamma model was employed [13]. The properties are obtained at the plateau region (burned products) were the fluid is at rest. These properties represent the pressure rise in detonation and therefore play a crucial role in defining the PDC performance.

The plateau stagnation temperature, $T_{b}$, and density, $\rho_{b}$, are obtained with the following relations:

$$
T_{b}=\frac{c_{b}^{2}}{\gamma_{b} R_{b}}
$$

$$
\rho_{b}=\frac{1}{R_{b} T_{b}} P_{b}
$$

$R_{b}$ is the products specific gas constant.

After the blowdown period $\left(t_{\text {plateau }}+t_{\text {decay }}\right)$ the tube is filled with hot products at $P_{i n}$. This period is here referred to as scavenge state and its properties are useful to determine PDC mass average outlet pressure. The scavenge density is given by an isentropic expansion between the plateau and scavenge states,

$$
\rho_{s}=\rho_{b}\left(\frac{p_{i n}}{p_{b}}\right)^{\frac{1}{\gamma_{b}}}
$$

\section{Cycle times}

A plot illustrating the PDC cycle times is given in Fig. 3, including a number of processes of the PDC operation that occur sequentially:

- Detonation initiation, this time is neglected in our formulation since we assume that a detonation wave is created instantaneously in the closed end of the tube (at the valve plane).

- Detonation propagation, this time is controlled by the length of the tube, $L$, and by the detonation and fill velocities:

$$
t_{\mathrm{CJ}}=\frac{L}{\mathrm{D}_{\mathrm{CJ}}+U_{f}}
$$

- Plateau time, can be decomposed into the sum of detonation time and the time it takes for the rarefaction wave to propagate from the open end to the closed end of the tube. This time can be expressed by:

$$
t_{\text {plateau }}=\delta_{B} t_{\mathrm{CJ}}
$$

$$
\delta_{B}=2\left(\frac{\gamma_{i n} \mathrm{M}_{\mathrm{CJ}}^{2}+\gamma_{b}}{\gamma_{i n} \mathrm{M}_{\mathrm{CJ}}^{2}+1} \cdot \frac{\gamma_{b}+1}{2 \gamma_{b}}\right)^{\frac{\left(\gamma_{b}+1\right)}{\left(\gamma_{b}-1\right)}}
$$

- $\quad$ The exhaust time, is the sum between the plateau and decay times,

$$
t_{\text {ex }}=t_{\text {plateau }}+t_{\text {decay }}
$$

The pressure decay time, 


$$
t_{\text {decay }}=t_{\mathrm{CJ}} \delta_{A 2}\left[f_{n \prime}\left(\delta_{A 1}\right)-1\right]
$$

is obtained with Eq. (13). The functions that represent the decay of pressure in the valve plane, $f_{n^{\prime}}\left(\delta_{A 1}\right)$, can be found in Table 1 of [13].

- The purge time and fill times, are the times it takes to fully or partially purge the hot gases from the PDC chamber and to completely fill the tubes with a fresh fuel-air mixture,

$$
t_{p}=\frac{L}{c_{g} \mathrm{M}_{f}} \quad t_{f}=\frac{L}{c_{f} \mathrm{M}_{f}}
$$

Where,

$$
c_{g}=\sqrt{\gamma_{\text {air }} R_{\text {air }} T_{\text {in }}} \quad c_{f}=\sqrt{\gamma_{i n} R_{\text {in }} T_{\text {in }}}
$$

assuming that the temperature for the fuel-air mixture and purge air is the same. In Eq. (15) the gas constants for air and fuel-air mixture are employed.

\section{Cycle averaged properties}

The final step of the PDC model is to calculate the cycle averaged pressure and temperature. The purge fraction is defined for a constant volume of the tubes:

$$
\beta=\frac{m_{p}}{m_{f}+m_{p}}=\frac{\rho_{p}}{\rho_{f}+\rho_{p}}
$$

Where, $\rho_{p}$ and $\rho_{f}$ are the purge and fuel-air mixture densities, respectively.

The averaged pressure during the exhaust phase is obtained by integrating the pressure function (see the shaded regions in Fig. 3) and dividing the result by the exhaust time,

$$
P_{\text {ex }}=\frac{\left(P_{b}-P_{\text {in }}\right) t_{\text {plateau }}+\int_{t_{\text {plateau }}}^{t_{\text {exhaust }}}\left(P(t)-P_{\text {in }}\right) d t}{t_{\text {ex }}}+P_{\text {in }}
$$

Using Endo et al. [13] analytical approximations of the exhaust averaged pressure can be obtained,

$$
P_{e x}=\frac{\left(P_{b}-P_{i n}\right)\left(F_{n^{\prime}}\left(\delta_{A 1}, \delta_{A 2}\right)+\delta_{B}\right) t_{\mathrm{CJ}}}{t_{e x}}+P_{\text {in }}
$$

The $F_{n^{\prime}}\left(\delta_{A 1}, \delta_{A 2}\right)$ functions can be found in [13], Table 2. The cycle averaged pressure can now be mass weighted using the fluid properties at different phases of the PDC cycle:

$$
P_{4}=P_{e x} \cdot\left(\frac{\rho_{f}-\rho_{s}}{\rho_{f}+\rho_{p}}\right)+P_{i n} \cdot\left(\frac{\rho_{p}+\rho_{s}}{\rho_{f}+\rho_{p}}\right)
$$

The temperature is obtained by iterating on the energy flows using the energy conservation equation,

$$
q_{4}=\left(1+f_{4}\right) \cdot \Delta h_{0,4-298 K}\left(T_{0,4}, f_{4}\right)-\Delta h_{0,1-298 K}\left(T_{0, \text { in }}\right)
$$

where the overall fuel-to-air mass ratio is balanced by the purge fraction and combustion efficiency [14],

$$
f_{4}=f \cdot \frac{(1-\beta)}{\eta_{b}}
$$

and the overall heat addition is $q_{4}=f_{4} \cdot$ LHV. The model will iterate on $T_{0,4}$ until $q_{4}$ is satisfied. The cycle-averaged fuel mass flow rate is given by:

$$
\dot{m}_{f u e l, 4}=f_{4} g_{3}
$$

\section{PDC Model Validation}

In this section the proposed PDC model is validated against in-house CFD results and against data available in the literature [21]. The in-house CFD results are used to verify the model capability in predicting some of the most important physical phenomena of detonation in tubes. The comparison with results from literature allows for a more comprehensive system-level validation, where performance data are compared with results of Perkins et al. [21], for three different pulse detonation systems at two different combustor and outlet conditions.

The in-house CFD validation data is obtained for detonation in a single tube with a stoichiometric mixture of $\mathrm{H}_{2}$-Air, at $p_{\text {in }}=$ $1 \mathrm{~atm}$ and $T_{i n}=300 \mathrm{~K}$. Filling was not modelled in the CFD computations. The length of the tube is $L=0.5 \mathrm{~m}$ and the diameter is $D=0.04 \mathrm{~m}$. The detonation is formed by using a high pressure $\left(p_{\text {trigger }}=60 \mathrm{~atm}\right)$ and high temperature $\left(T_{\text {trigger }}=3000 \mathrm{~K}\right)$ driver gas, consisting of nitrogen and water vapor, in a small region $\left(L_{\text {trigger }}=0,005 \mathrm{~L}\right)$ near to the closed end of the tube. The implemented numerical method is based on the finite-volume implementation of the axisymmetric multispecie Euler equations [25]. The finite-rate reactions are calculated with Arrhenius kinetic expressions and, due to the supersonic nature of the flame, a laminar finite-rate model was selected. A detailed chemical mechanism comprising 19 elementary reversible reactions and nine species was used to model detonation [26]. For time discretization a dual-time formulation was employed, which includes the second order Euler backward implicit method for advancing in physical time, and a pseudo-time marching 3-stage Runge-Kutta for the inneriterations. A CFL-based stability condition was used to select the pseudo-time step within the inner iterations, while a constant value was assumed for the physical time-step ranging from $10^{-8} \mathrm{~s}$ to $10^{-9} \mathrm{~s}$ during detonation initiation and propagation. The Roe flux-difference splitting scheme was 
selected to evaluate the convective fluxes and for variable interpolation the second order upwind scheme with a TVD Minmod based slope limiter. Material properties for the mixture were obtained using the mixing-law and the ideal gas law.

A comparison between the analytical and CFD results is given in Table 1. The deviation between the models is approximately $2 \%$ for the computation of the plateau properties and exhaust time.

TABLE 1 - COMPARISON BETWEEN IN-HOUSE CFD AND ANALYTICAL RESULTS.

\begin{tabular}{llll}
\hline & $P_{b}(\mathrm{~atm})$ & $T_{b}(\mathrm{~K})$ & $t_{\text {ex }}(\mathrm{s})$ \\
\hline CFD & 5.75 & 2515 & 0.001565 \\
Analytical & 5.83 & 2571 & 0.001584 \\
deviation & $1.4 \%$ & $2.2 \%$ & $1.2 \%$ \\
\hline
\end{tabular}

The system level implementation was also validated against literature data $[16,21]$ for three different PDC-axial turbine/nozzle implementations, operating with propane at different OPR (compressor) and PDC conditions. The simplified engine model included a compressor, with isentropic efficiency of $90 \%$, a PDC and an isentropic expander. The two different PDC conditions were simulated for different altitudes, freestream Mach numbers and inlet total pressure recoveries to match the desired PDC inlet properties: case $1, P_{\text {in }}=342.6 \mathrm{kPa}$, $T_{0, i n}=441.5 \mathrm{~K}$ and $\phi_{4}=0.47$; case $2, P_{\text {in }}=355.8 \mathrm{kPa}$, $T_{0, \text { in }}=433.2 \mathrm{~K}$ and $\phi_{4}=0.54$. The nozzle backpressure is $33.9 \mathrm{kPa}$ for case 1 and $30.7 \mathrm{kPa}$ case 2. Different local equivalence ratios were specified for each case: $\phi=0.95$ for case 1 ; and $\phi=1.1$ for case 2 , and the purge and non-purge flows are balanced to achieve a desired overall equivalence ratio.

Figure 4 shows a comparison between the current model specific impulse results and data obtained by Perkins et al. [21], using a quasi-one-dimensional CFD code. For reference the plot also shows a $\pm 5 \%$ deviation bar around Perkins case 1 at OPR of 3.0. It is evident that for this, and other cases the difference between the current results and literature specific impulse data is less than $5 \%$.

\section{ENGINE CYCLE EVALUATION}

The H2020 ULTIMATE project aims to explore radical aircraft propulsion design concepts, and down-select the most promising candidate, targeting entry in to service at year 2050. To quantify the contribution arising from the potential PDC 'ULTIMATE' configuration, baseline year 2000 and reference year 2050 aircraft-powerplant configurations have been modelled. The 2050 version is based on 'conventional turbofan technological developments' assumed to be available by year 2050, supported by related public domain literature and the consensus of ULTIMATE consortium industry partners. To support the successful execution of this study, this ULTIMATE year 2050 'reference engine' configuration and its performance data have been adopted to support assessment of the proposed

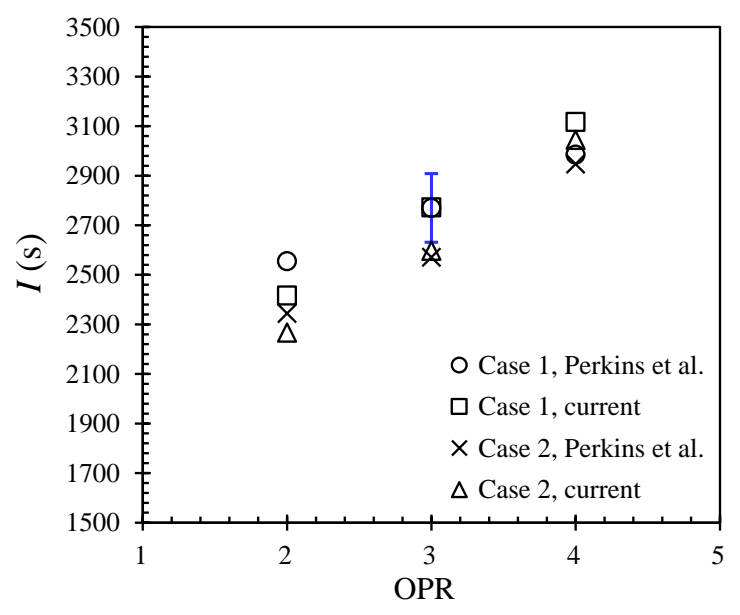

FIGURE 4 - COMPARISON BETWEEN CURRENT RESULTS AND PERKINS ET AT. DATA [21]. THE BLUE BAR ILUSTRATES A 5\% DEVIATION.

advanced intercooled PDC engines. Table 2 summarizes the component efficiencies for the reference engine at cruise conditions.

The reference engine cycle represents an ultra-high bypass ratio geared turbofan intended for long-range operations. The performance data for three different mission points are given in Table 3. A typical long-range aircraft may spend typically 90$95 \%$ of its total mission time at cruise condition. Therefore the engine performance at mid-cruise serves as a good indicator to represent its average performance within the overall cruise phase of the mission. The maximum take-off represents the operating point at the end of a runway. This particular point represents the most demanding operating condition in terms of aircraft power requirements, as tabulated in Table 3 . The maximum climb condition is at the end of the climb. The reference engine model schematic and station numbering are illustrated in Figure 5. The blue/dashed modules represent the proposed advanced intercooled, aftercooled and non-precooled PDC cycles, to be elaborated in the following sections.

TABLE 2 -COMPONENT EFFICIENCIES FOR THE REFERENCE 2050 ENGINE AT CRUISE

\begin{tabular}{cc}
\hline Parameter & Value \\
\hline$\eta_{p, \text { FAN }}$ & 0.95 \\
$\eta_{p, \mathrm{IPC}}$ & 0.92 \\
$\eta_{p, \mathrm{HPC}}$ & 0.91 \\
$\eta_{s, \mathrm{HPT}}$ & 0.91 \\
$\eta_{s, \mathrm{LPT}}$ & 0.95 \\
$\eta_{b}$ & 0.999 \\
\hline
\end{tabular}




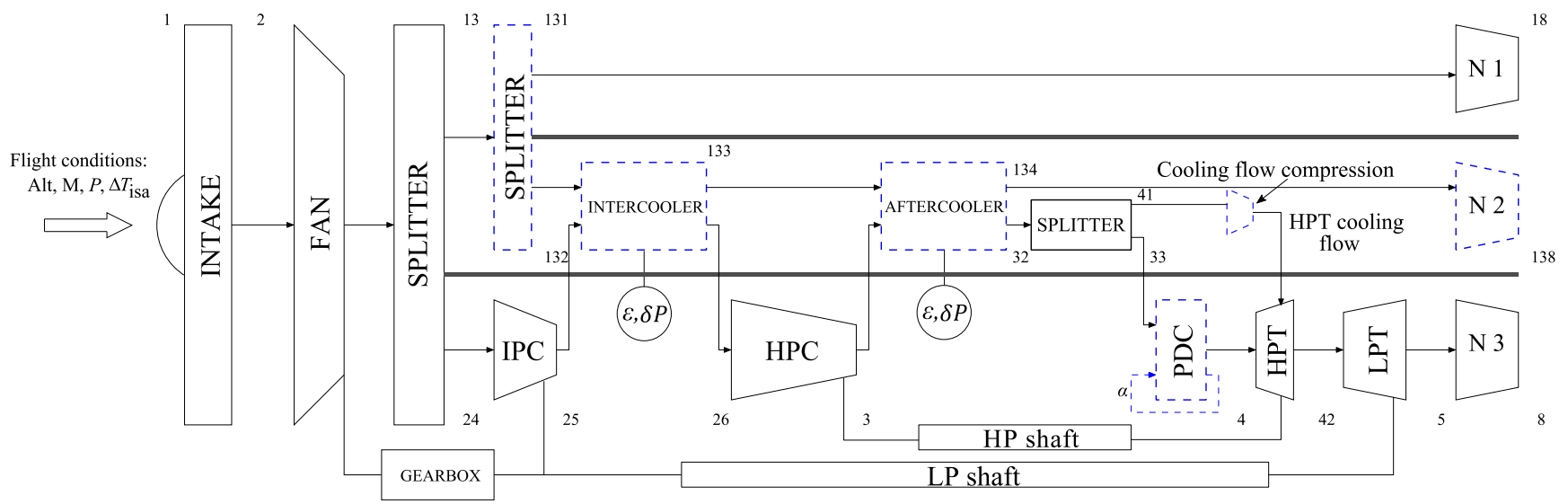

FIGURE 5 - PERFORMANCE MODEL SCHEMATICS FOR THE REFERENCE, INTERCOOLED AND AFTERCOOLED ENGINES.

TABLE 3 - PERFORMANCE RESULTS OBTAINED FOR THE REFERENCE ULTRA-HIGH BYPASS RATIO TURBOFAN ENGINE.

\begin{tabular}{cccc}
\hline Parameter & Mid-Cruise & Max Climb & Max Takeoff \\
\hline Alt. $(\mathrm{m})$ & 10,668 & 10,668 & 0.0 \\
Mach & 0.82 & 0.82 & 0.25 \\
TET $(\mathrm{K})$ & 1580 & 1890 & 1950 \\
$T_{3}(\mathrm{~K})$ & 873 & 989 & 1057 \\
OPR & 64.0 & 72.0 & 60.4 \\
$\pi_{\text {HPC }}$ & 20.1 & 24.5 & 22.2 \\
FPR & 1.33 & 1.43 & 1.34 \\
BPR & 20.4 & 20.0 & 19.3 \\
$F_{S}(\mathrm{~m} / \mathrm{s})$ & 72 & 93 & 154 \\
SFC $(\mathrm{mg} / \mathrm{N} . \mathrm{s})$ & 12.8 & 13.5 & 8.6 \\
\hline
\end{tabular}

\section{Geared turbofan cycle with PDC}

The conventional combustion system of the reference engine is replaced by a PDC, as illustrated in Fig. 5, to model an engine without any pre-cooling ahead of the PDC. The cycle averaged temperature is limited to the reference cycle mid-cruise TET by balancing the purge and non-purge flows (iterating on purge fraction). On the other hand no limitation is imposed on the combustor exit pressure. The high pressure turbine efficiency is reduced to $87 \%$ to account for the losses arising from the interaction with PDC flow, based on the findings reported in [27], and no penalty is put on the efficiency of the compressors and low pressure turbine. The local equivalence ratio is $\phi=0.7$, which is above the lower limit for detonation in vaporized Jet-Aair mixtures [28]. The fill and purge Mach number is fixed at $\mathrm{M}_{f}=0.5$. The cycles are compared at mid-cruise for a constant thrust and specific thrust, so for an optimized FPR the differences in SFC reflect the changes in the thermal and transfer efficiencies alone. The fan pressure ratio has been kept the same as in the reference cycle.

Figure 6-a) shows the variation of $\triangle \mathrm{SFC}$ and relative thermal efficiency, $\Delta \eta_{t h}$, with OPR. The variation in $\Delta \mathrm{SFC}$ and thermal efficiency are relative to the reference engine at midcruise, see Table 3 . Results clearly show that the thermodynamic benefits of detonation are more pronounced at lower OPR. This result is aligned with previous findings [9] and is mainly due to the higher combustion pressure ratios that are achievable at lower compressor delivery temperatures. Figure 6-a) also shows that a $6 \%$ SFC improvement is theoretically possible by replacing the conventional burner with a detonation core at design OPR of 64. The variation of BPR with OPR is plotted in Figure 6-b). The replacement of a conventional burner by a detonation chamber increases the BPR due to an increase in core power density. This trend also diminishes as the OPR increases, which is attributed to two factors. Firstly, an increase in HPC delivery temperature leads to a decrease in detonation pressure ratio, $p_{\mathrm{CJ}} / p_{\text {in }}$. Secondly, due to an increase in $T_{3}$ with OPR, the purge fraction, $\beta$, also increases, which will further contribute to a decrease in the detonation cycle average pressure ratio $\pi_{c}=$ $P_{4} / P_{\text {in }}$.

\section{Cooling Requirements}

The two-stage HP turbine has cooled metallic nozzle guide vanes in the first stage, whereas the second stage has un-cooled ceramic matrix composite (CMC) stators. The rotor blades are cooled and the HPT shroud is CMC. The entire HPT is cooled with HP compressor exhaust air. However, the bleed cooling air is at a lower pressure and requires further compression in order to match the PDC outlet pressure and to provide a pressure margin to enter the core through the vane and rotor cooling passages. A radial compressor is therefore placed between the splitter and HPT, and the power necessary to drive the radial compressor is extracted from the shaft. A compression efficiency of $90 \%$ is assumed for the cooling flow compression system. The mathematical model used to estimate the cooling requirements is based on the work of Wilcock et al. [29]. 


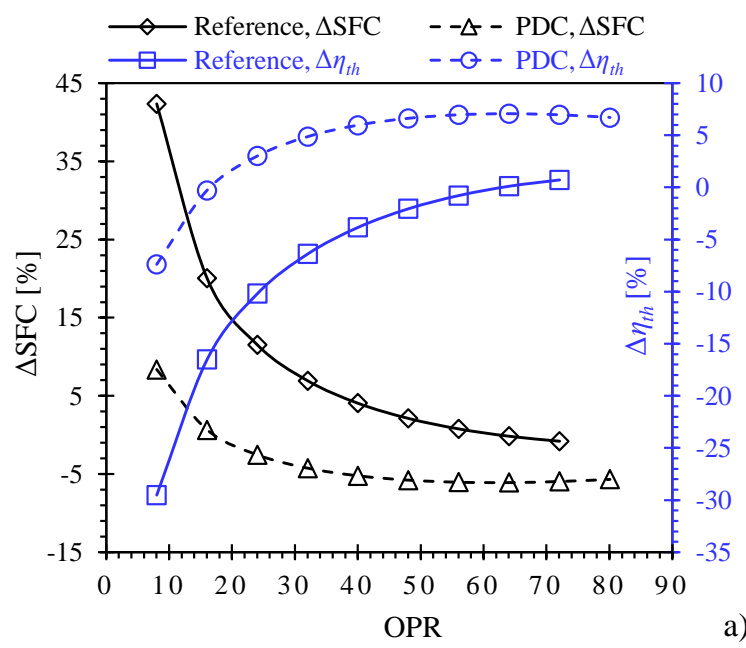

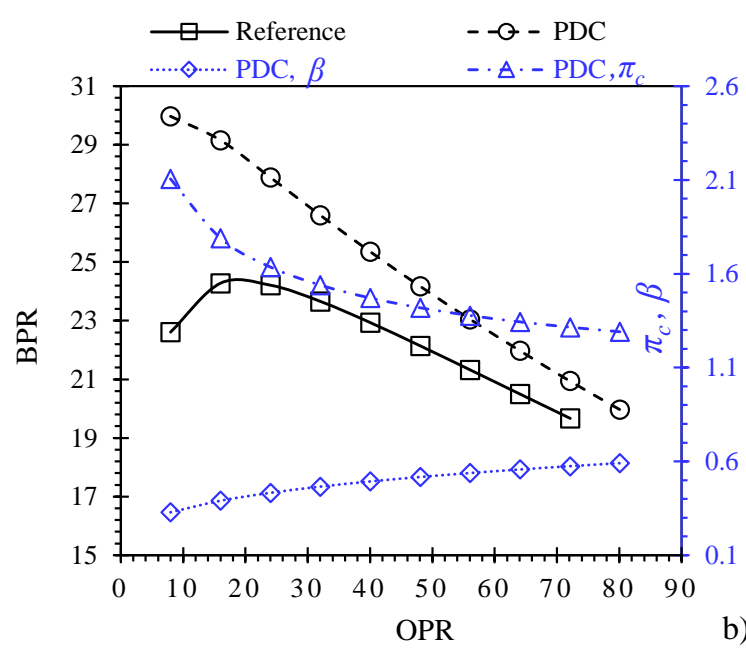

FIGURE 6 - VARIATION OF $\Delta$ SFC, THERMAL EFFICIENCY $\left(\Delta \eta_{t h}\right)$, BPR, COMBUSTOR PRESSURE RATIO $\left(\pi_{c}\right)$, AND PURGE FRACTION $(\beta)$ WITH OPR. RESULTS OBTAINED FOR THE NON-PRECOOLED PDC.

\section{Intake valve}

The unsteady nature of the PDC cycle requires the integration of a high frequency intake valve. Different valve concepts for pulse detonation engines can be found in the revision work of Roy et al. [18]. These include the usage of poppet, rotary and sleeve valves. Poppet valves, which are widely used in the automotive industry, are more mature and therefore more reliable for high frequency operation. However, for a given level of losses, one expects that the poppet valve will need to be bigger and heavier than the rotating valve. The present performance study is based on a partly idealized function of the pulse detonation tubes. Under the assumption of instantaneous detonation initiation, the tube length and firing frequency do not directly enter in the performance estimation. Without fixing these parameters the requirements on a valve mechanism, including the speed at which the valve opens and closes, cannot be determined. As a consequence, an accurate prediction of the average pressure loss through the valve cannot be estimated at this stage. A simplified model is therefore used. The valve is considered as a sudden expansion with a complete loss of dynamic pressure, a Mach number of 0.2 at the valve should result in a total pressure loss of about 3\%. Figure 7 shows the variation of the relative SFC with an increase in valve pressure loss for different OPR levels. The variation in $\triangle \mathrm{SFC}$ is again relative to the reference engine at mid-cruise. Results show that a $1 \%$ pressure loss in the valve results into a $0.3 \%$ penalty in SFC. It is also clear that if the design fails to provide a valve pressure loss lower than $5 \%$, at cruise, than the benefits arising from PDC at high OPR will be almost insignificant. However, it is likely a design is possible which would retain the major part of the gains over a conventional combustor. The use of inter- and aftercooling will reduce the required valve area and serve to limit valve temperatures of the tube.

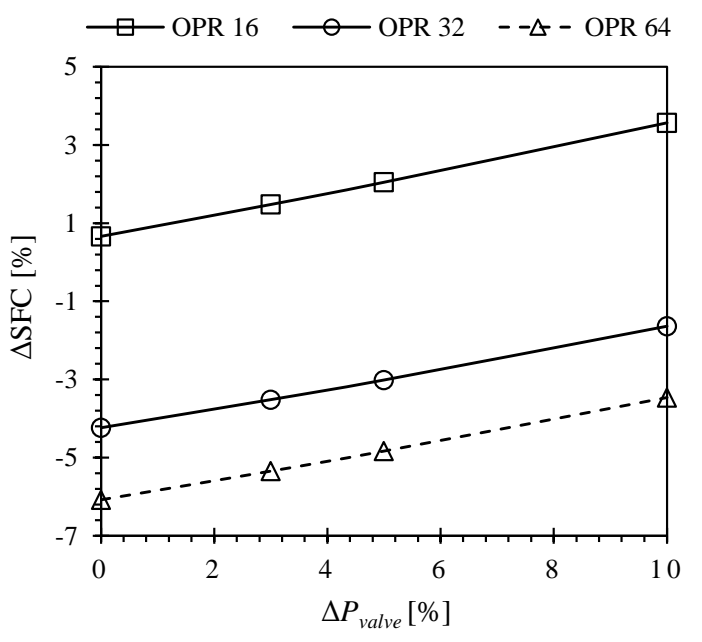

\section{FIGURE 7 - EFFECT OF VALVE PRESSURE LOSS IN $\triangle$ SFC FOR THE NON PRE-COOLED PDC AT DIFFERENT OPR.}

\section{Intercooled PDC cycle}

An intercooler is installed inside the bypass duct to model the performance characteristics of an intercooled PDC cycle. This location is consistent with the proposed arrangement reported in studies dedicated to the exploration of intercooling for high bypass ratio turbofans [5, 7, 30, 31]. The considered arrangement allows for an efficient installation of a compact airto-air cross-flow heat exchanger as well as to recovering thrust by ejecting the spent cooling air using a variable area nozzle. A simplified intercooler model is used in the current analysis. The model accepts as inputs temperature effectiveness, $\varepsilon$, here defined as, 


$$
\varepsilon=\frac{T_{25}-T_{26}}{T_{25}-T_{132}}
$$

The inner pressure losses, $\delta P_{\text {inner }}$, outer pressure losses, $\delta P_{\text {outer }}$, and cooling-air to core flow ratio, $g_{132} / g_{25}$ are additional inputs to the model.

The intercooler is located between the IPC and HPC compressors. The pressure ratio of the IPC was adjusted to keep a constant pressure ratio split exponent, $n$ [32],

$$
n=\log _{\mathrm{OPR}}\left(\frac{P_{25}}{P_{2}}\right)
$$

of 0.4 over the entire range of OPR, to match the optimum value of Zhao et al. [5]. According to Kyprianidis et al. [32] a lower $n$ benefits the engine thermal efficiency but leads to an increase in
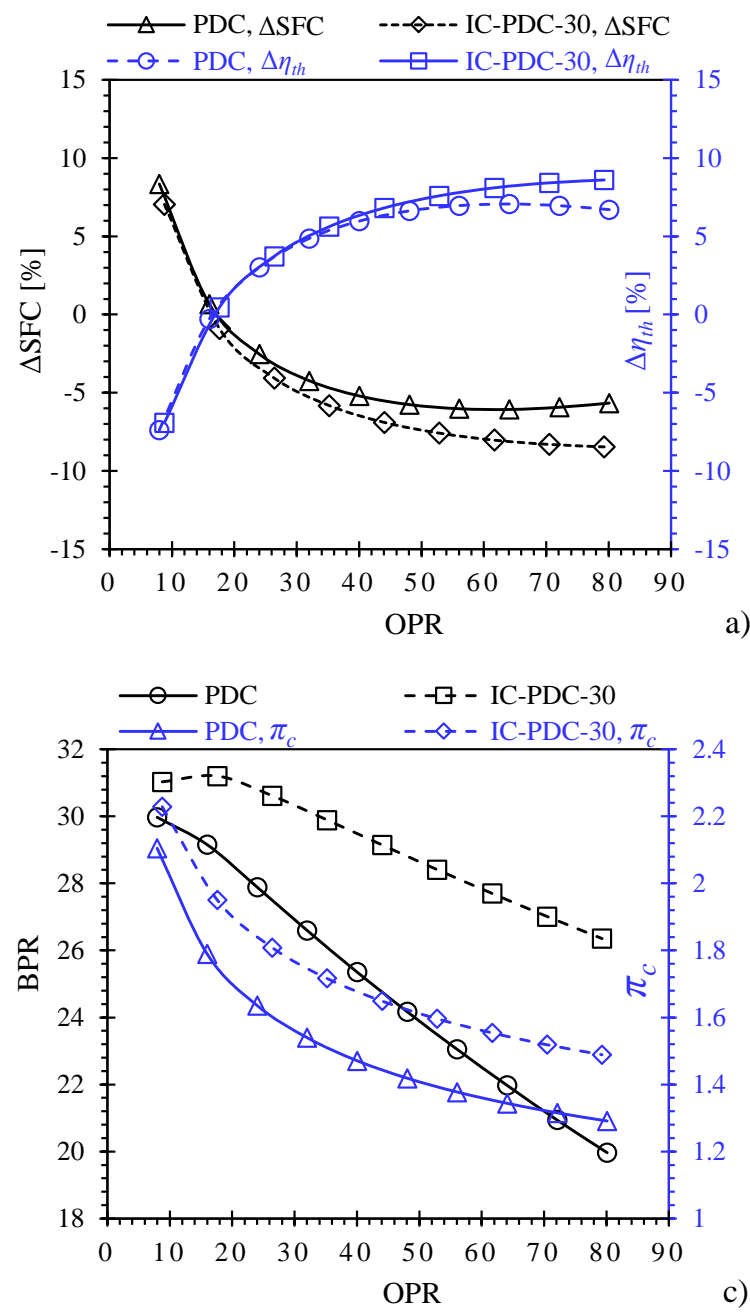

engine weight and intercooler volume. Conversely, a higher $n$ moves the intercooler further into the compression system, tending to reduce pressure losses and weight. The pressure ratio split exponent in the reference configuration of Table 3 is around 0.28 . Therefore it can be expected that an optimal design will have a higher OPR and IPC pressure ratio than the reference engine configuration.

\section{TABLE 4 - INTERCOOLER HEAT EXCHANGER PERFORMANCE DATA [5].}

\begin{tabular}{lccccc}
\hline & $\begin{array}{c}\text { Rel. cooling } \\
\text { nozzle area }\end{array}$ & $\begin{array}{l}g_{132} / \\
g_{25}\end{array}$ & $\delta P_{\text {inner }}$ & $\delta P_{\text {outer }}$ & $\varepsilon$ \\
\hline IC-PDC-30 & $30 \%$ & 0.75 & 0.04 & 0.03 & 0.54 \\
IC-PDC-100 & $100 \%$ & 2.2 & 0.04 & 0.07 & 0.72 \\
\hline
\end{tabular}
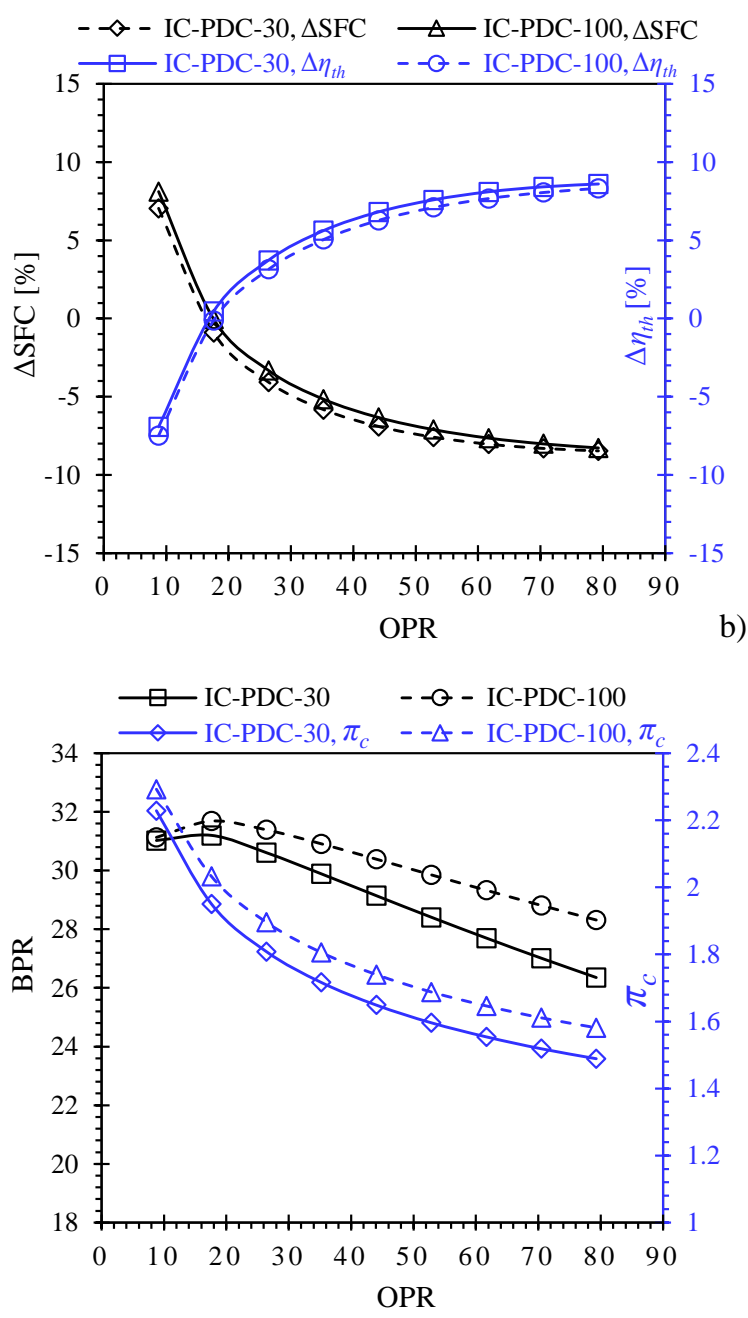

FIGURE 8 - VARIATION OF $\Delta$ SFC, THERMAL EFFICIENCY $\left(\Delta \eta_{t h}\right)$, BPR, COMBUSTOR PRESSURE RATIO $\left(\pi_{c}\right)$ WITH OPR (COMPRESSIOR). IC-PDC-30/100: INTERCOOLED PDC CORE WITH N2 AREA AT 30\% AND $100 \%$. 
The amount of air used on the intercooler cooling side, $g_{132}$, is controlled by the area of the cooling flow nozzle N2, see Fig. 5. Increasing it increases the heat transfer rate but increases the cooling-side flow pressure losses, $\delta P_{\text {outer }}$. Two different cooling nozzle openings are analyzed with the performance data of Table 4 . The inner, $\delta P_{\text {inner }}$, and outer pressure losses are obtained from previous intercooler conceptual design studies $[31,5]$.

Figure 8 shows a comparison between the performance results obtained for the non-precooled detonation (PDC) and intercooled detonation cores (IC-PDC) at different variable nozzle areas. The variation in $\triangle \mathrm{SFC}$ and thermal efficiency are again relative to the reference engine at mid-cruise, see Table 2. With a 30\% (IC-PDC-30) nozzle area the results of Fig. 8-a) show an improvement of SFC for OPR higher than 10. For an OPR of 64 the SFC improvement over the non-precooled detonation core is around 2\%. Figure 8-c) shows, for an OPR of 64 , a $15 \%$ increase in combustor pressure ratio, $\pi_{c}$, when an intercooler is used in the cycle. Such behavior is linked to the lower PDC inlet temperature that results in an increase in detonation pressure ratio $p_{\mathrm{CJ}} / p_{\text {in }}$, and a decrease of around $16 \%$ in purge fraction, $\beta$, to give the same average turbine entry temperature, see Fig. 9c). The HPT turbine cooling mass flow is also reduced due to the lower temperature of the cooling flow in the intercooled cycle.

Figure 8-c) shows that the BPR is affected by the presence of the intercooler and that the difference between the nonprecooled detonation and intercooled detonation BPR increases with OPR. This is due to the fact that the intercooler effectiveness is kept constant for the entire range of OPR, thus the intercooler heat exchange rate, and the consequent temperature drop, increases with OPR.

With a fully opened nozzle (IC-PDC-100) the penalties in thermal efficiency and SFC increase for the entire range of OPR's, see Fig. 8-b). On the other hand the combustor pressure ratio and BPR also increase, see Fig. 8-d), due to an increase in core flow temperature drop and a decrease in purge fraction (Fig. 9 -c). This behavior suggests that the mass flow ratio $g_{132} / g_{25}$ plays an important role in design and should be included in an optimization study.

\section{Intercooled-Aftercooled PDC cycle}

A second heat exchanger was placed in the same duct at a downstream location to the intercooler, and used to cool the HPC delivery air. This heat exchanger is referred to as an aftercooler (AC) due to its location right after the compression system as illustrated in Fig. 5. For the purpose of this study, the design features of the AC were maintained similar to those of the IC (e.g. in terms of effectiveness and pressure loses). However, due to the downstream location of the $\mathrm{AC}$, it could be expected that a more compact heat exchanger could be incorporated, which may suggest that the pressure losses in the cold side might also decrease. However, from the conceptual design point of view, it is deemed acceptable to model the AC design features similar to the IC to gain an initial understanding of the cycle performance.
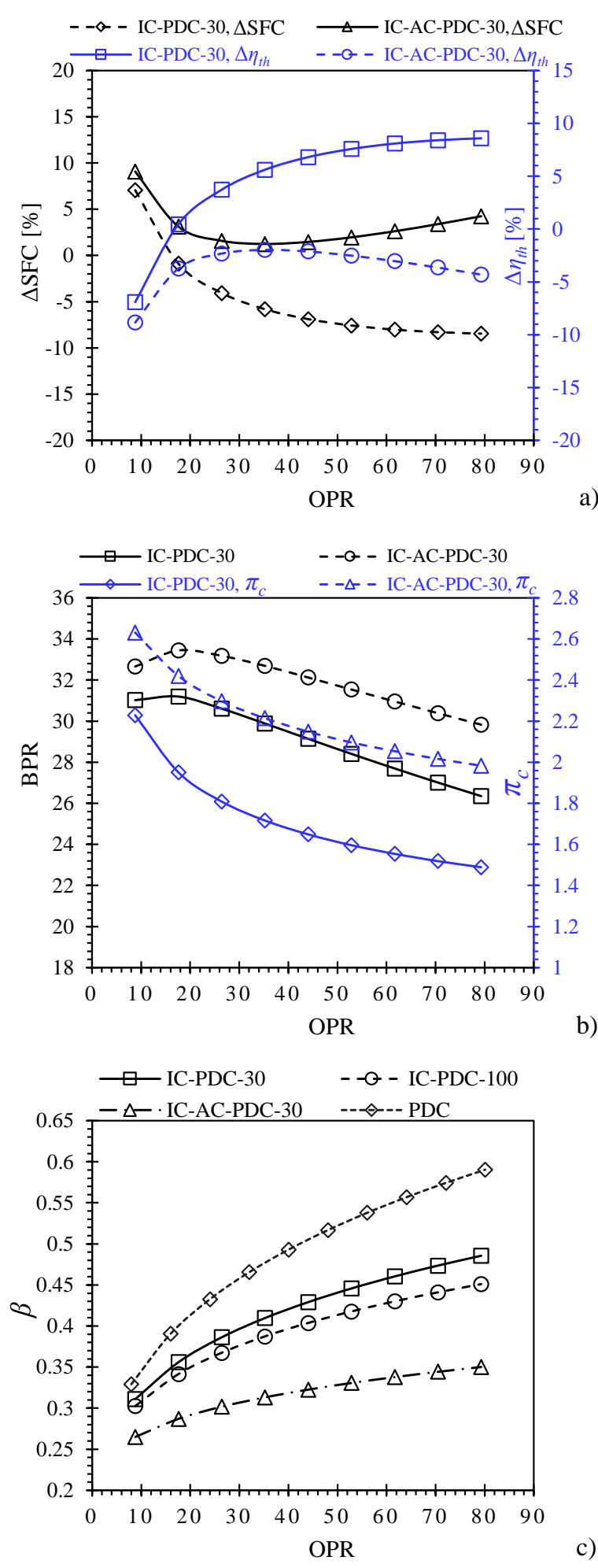

FIGURE 9 - VARIATION OF $\triangle$ SFC, THERMAL EFFICIENCY $\left(\Delta \eta_{t h}\right)$, BPR, COMBUSTOR PRESSURE RATIO $\left(\pi_{c}\right)$ AND PURGE FRACTION $(\beta)$ WITH OPR (MECHANICAL). 
The performance results for the intercooled-aftercooled PDC with a $30 \%$ opening (IC-AC-PDC-30) are compared with the intercooled case, with the same opening, in Fig. 9. The variations in $\triangle \mathrm{SFC}$ and thermal efficiency are again relative to the reference engine at mid-cruise, see Table 2 . It is evident that the incorporation of aftercooling results in significant penalties in terms of $\triangle \mathrm{SFC}$ and relative thermal efficiency. This is primarily attributed to the fact that the temperature drop across the AC increases with OPR. Still, the specific power increases due to an increase in combustor pressure ratio and a decrease in purge fraction. Nonetheless, the extra weight of a second heat exchanger could cancel the potential core weight benefit at cruise. Furthermore, these results also reveal that the penalties in SFC are between $10-14 \%$, relative to an intercooled PDC cycle, which outweighs the benefits arising from the inclusion of detonation during cruise. However, an aftercooler might prove itself useful during high power requirements like take-off and climb conditions. Therefore, intercooling and aftercooling variability in off-design conditions will be the subject of future research.

\section{CONCLUSIONS}

In the present work a one-dimensional PDC model was developed and integrated within a gas turbine engine design tool. The model capability to predict important phenomena of detonation in tubes was verified by comparison with in-house CFD results. A comparison with performance data for a simplified pulse detonation engine revealed that the system level integration of the model was adequate for the scope of the current study.

Based on the successful implementation of the proposed model four different engine architectures were analyzed, comprising a reference engine (conventional burner), a nonprecooled PDC engine, an intercooled-PDC engine and an intercooled-aftercooled PDC engine. The acquired results obtained for different performance metrics and cycle parameters indicate that, for the technology levels assumed to be available by 2050 , the improvements in uninstalled SFC and thermal efficiency are around $6 \%$ if a conventional burner is replaced by a pulse detonation combustion system. A promising synergy between intercooling and pulse detonation was also identified. Results show that a core size reduction is achievable and an improvement in SFC could be expected for the entire range of OPR. Results for the IC-PDC design also suggest that a high OPR PDC cycle could be a viable solution if the technological challenges associated with detonation can be met. These challenges include:

- The design of a system that allows the operation at high frequency and promotes detonation initiation and propagation at lowest pressure loss.

- Development of efficient air supply and fuel injection systems to ensure a quasi-homogenous mixing and tube filling with minimum pressure loss and filling time.

- Control methodology that allows for variability during the entire flight mission (gate-to-gate). The system should use high frequency actuating valves, and should allow for a deflagration mode during idle conditions.

- Combustor cooling system, heat removal from combustor walls to avoid pre-ignition. Ideally the lost heat should be recuperated in the cycle.

- Low-energy source detonation initiation mechanism.

- Efficient coupling of multi-tube PDC. Sequential detonation can affect the purging and filling phases of adjacent tubes leading to unstable operation.

- Effective integration of a downstream turbine.

- Development of a robust design. The structural components of a PDC are subjected to high frequency thermal deformations and shock loading.

The integration of some of the aforementioned assumptions is straightforward in the proposed model (e.g. pressure losses in valve and HPT cooling methodology), while others are more difficult to integrate. Nevertheless, the present results indicate that a pre-cooled pulse detonation core should be the subject of a more detailed conceptual design and optimization study.

The results obtained with the aftercooled architecture revealed that the penalties in SFC are between $10 \%$ and $14 \%$ for the OPR range 50-80 and outweigh any benefits arising from the inclusion of IC and PDC. However aftercooling also increases the specific power of the cycle, and it might be a necessary feature for high OPR PDC engines in order to reduce the HPC delivery temperature to acceptable values, reducing the risk of pre-detonation particularly at take-off.

\section{ACKNOWLEDGMENTS}

This work is financially supported by the E.U. under the "ULTIMATE - Ultra Low Emission Technology Innovations for Mid-century Aircraft Turbine Engines" Project co-funded by the European Commission within the Horizon 2020 Programme (2014-2020) under Grant Agreement no. 633436.

\section{REFERENCES}

[1] T. Grönstedt, C. Xisto, V. Sethi, A. Rolt, N. G. Rosa, A. Seitz, K. Yakinthos, S. Donnerhack, P. Newton, N. Tantot, O. Schmitz and A. Lundbladh, "Ultra Low Emission Technology Innovations for Mid-Century Aircraft Turbine Engines," in ASME Turbo EXPO 2016, Seoul, South Korea, 2016.

[2] T. Grönstedt, M. Irannezhad, X. Lei, O. Thulin and A. Lundbladh, "First and Second Law Analysis of Future Aircraft Engines," Journal of Engineering for Gas Turbines and Power, vol. 136, no. 3, pp. 031202031202-10, 2014.

[3] N. G. Rosa, G. Dufour, R. Barènes and G. Lavergne, "Experimental Analysis of the Global Performance and the Flow Through a High-Bypass Turbofan in Windmilling Conditions," ASME. J. Turbomach, vol. 137, no. 5, pp. 051001-051001-8, 2015. 
P. Bellocq, I. Garmendia, V. Sethi, A. Patin, S. Capodanno and F. R. Lucas, "Multidisciplinary Assessment of the Control of the Propellers of a Pusher Geared Open Rotor-Part II: Impact on Fuel Consumption, Engine Weight, Certification Noise, and NOx Emissions," ASME. J. Eng. Gas Turbines Power, vol. 138, no. 7, pp. 072603-072603-8, 2016.

[5] X. Zhao, O. Thulin and T. Grönstedt, "First and Second Law Analysis of Intercooled Turbofan Engine," Journal of Engineering for Gas Turbines and Power, vol. 138, no. 2, pp. 021202-021202-8, 2015.

[6] K. Kyprianidis, T. Grönstedt, S. Ogaji, P. Pilidis and R. Singh, "Assessment of Future Aero-engine Designs With Intercooled and Intercooled Recuperated Cores," J. Eng. Gas Turbines Power, vol. 133, no. 1, pp. 011701-011701-10, 2010.

[7] K. G. Kyprianidis and A. Rolt, "On the Optimization of a Geared Fan Intercooled Core Engine Design," J. Eng. Gas Turbines Power, vol. 137, no. 4, pp. 041201-041201-10, 2015.

[8] S. Kaiser, A. Seitz, S. Donnerhack and A. Lundbladh, "Composite Cycle Engine Concept with Hectopressure Ratio," in 51st AIAA/SAE/ASEE Joint Propulsion Conference, Propulsion and Energy Forum, Cleveland, Ohio, 2015.

[9] W. Heiser and D. T. Pratt, "Thermodynamic Cycle Analysis of Pulse Detonation Engines," Journal of Propulsion and Power, vol. 18, no. 1, pp. 68 - 76, 2002.

[10] A. St. George, R. Driscoll, E. Gutmark and M. D., "Experimental Comparison of Axial Turbine Performance Under Steady and Pulsating Flows," ASME. J. Turbomach., vol. 136, no. 11, pp. 111005111005-11, 2014

[11] K. Rouser, P. King, F. Schauer, R. Sondergaard, J. Hoke and L. Goss, "Time-Resolved Flow Properties in a Turbine Driven by Pulsed Detonations," Journal of Propulsion and Power, vol. 30, no. 6, pp. 1528 1536, 2014.

[12] E. Wintenberger and J. E. Shepherd, "Model for performance of airbreathing pulse-detonation engines," Journal of propulsion and power, vol. 22, no. 3, pp. 593-603, 2006.

[13] T. Endo, J. Kasahara, A. Matsuo, K. Inaba, S. Sato and T. Fujiwara, "Pressure history at the thurst wall of a simplified pulse detonation engine," AIAA Journal, vol. 42, no. 9, pp. 1921-1930, 2004.

[14] F. Ma, J.-Y. Cho and V. Yang, "Propulsive Performance of Airbreathing Pulse Detonation Engines," Journal of Propulsion and Power, vol. 22, no. 6, pp. 1188-1203, 2006.

[15] D. E. Paxson, "Performance Evaluation Method for Airbreathing Pulse Detonation Engines," Journal of Propulsion and Power, vol. 20, no. 5, pp. 945-947, 2004.

[16] J. Goldmeer, V. Tangirala and A. Dean, "SystemLevel Performance Estimation of a Pulse Detonation Hybrid Engine," J. Eng. Gas Turbines Power, vol. 130, no. 1, pp. 011201-011201-8, 2008.

[17] J. B. Heywood, Internal Combustion Engine Fundamentals, New York: McGraw-Hill, 1988.

[18] G. Roy, S. Frolov, A. Borisov and D. Netzer, "Pulse detonation propulsion: challenges, current status, and future perspective," Progress in Energy and Combustion Science, vol. 30, pp. 545 - 672, 2004.

[19] T. Grönstedt, Development of methods for analysis and optimization of complex jet engine systems, Göteborg: Ph.D theis, Chalmers University of Technology, 2000.

[20] R. Bellini and F. Lu, "Exergy Analysis of a Pulse Detonation Power Device," Journal of Propulsion and Power, vol. 26, no. 4, pp. 875-877, 2010.

[21] H. Perkins, D. Paxson, L. Povinelli, D. Petters, S. Thomas, J. Fittje and R. Dyer, "An Assessment of Pulse Detonation Engine Performance Estimation Methods Based on Experimental Results," in 41st AIAA Joint Propulsion Conference, July 10-13, Tuscon, Arizona,, 2005.

[22] M. Kaneshige and J. Shepherd, "Detonation database. Technical Report FM97-8," Caltech, GALCIT, 1997.

[23] K. Kailasanath, "Recent Developments in the Research on Pulse Detonation Engines," AIAA Journal, vol. 41, no. 2, pp. 145 - 159, 2003.

[24] B. McBride and S. Gordon, "Computer Program for Calculating and Fitting Thermodynamic Functions," NASA, 1992.

[25] ANSYS, ANSYS Fluent Theory Guide, ANSYS Inc., 2016.

[26] S. Yungster and K. Radhakrishnan, "Pulsating one-dimensional detonations in hydrogen-air mixtures," Combust. Theory Modelling, vol. 8, pp. 745-770, 2008.

[27] A. Suresh, D. C. Hofer and V. E. Tangirala, "Turbine Efficiency for Unsteady, Periodic Flows," Journal of Turbomachinery, vol. 134, no. 5, pp. 034501-034501-6, 2012.

[28] E. K. Dabora, "Lean Detonation Limit of Sensitized Kerosene Sprays in Air," in Dynamics of Detonations and Explosions, Progress in Astronautics and Aeronautics, American Institute of Aeronautics and Astronautics, 1990, pp. 311-324.

[29] R. C. Wilcock, J. B. Young and J. H. Horlock, "The Effect of Turbine Blade Cooling on the Cycle Efficiency of Gas Turbine Power Cycles," ASME J. 
Eng. Gas Turbines Power, vol. 127, no. 2, pp. 109120, 2005.

[30] L. Xu and T. Grönstedt, "Design and Analysis of an Intercooled Turbofan Engine," Journal of Engineering for Gas Turbines and Power, vol. 132, no. 11, pp. 114503-1-4, 2010.

[31] X. Zhao and T. Grönstedt, "Conceptual design of a two-pass cross-flow aeroengine intercooler," Proc
IMechE Part G: J Aerospace Engineering, vol. 229, no. 11, pp. 2006-2023, 2015.

[32] K. Kyprianidis, A. Rolt and T. Grönstedt, "Multidisciplinary Analysis of a Geared Fan Intercooled Core Aero-Engine," J. Eng. Gas Turbines Power, vol. 136, no. 1, pp. 011203-011203-11, 2014. 